\title{
Myriad Model
}

National Cancer Institute

\section{Source}

National Cancer Institute. Myriad Model. NCI Thesaurus. Code C62748.

A model that predicts a person's risk of hereditary breast and ovarian cancer based on family cancer history (including relatives' age at diagnosis) and ethnicity. 